\section{A time for taxonomists to take the lead}

The argument is often made that taxonomic information constitutes a key tool for conservation planning and sustainable natural resource management, and that without a reliable taxonomy or accurate data on where species occur, it would be difficult to achieve meaningful conservation planning. However, although most taxonomists recognize the fundamental role that our discipline plays in conservation, it is distressing how few of us actually devote time to the conservation effort. Taxonomists do make important contributions to specialist groups working as part of the IUCN's Species Survival Commission, providing a vital foundation for the development of action plans and red lists (http:// iucn.org/themes/ssc/index.htm), and others participate in local or national efforts to protect endangered species. Nevertheless, too few taxonomists, and the institutions for which they work, have found the need or motivation to assume an active role in conservation, preferring to focus on research. During the last few decades we taxonomists have increasingly had to seek financial support for our work from agencies and organizations which are, understandably, more concerned with helping to address global conservation issues than with basic science. It is now time for us to take stock of the contribution that we are making to biodiversity conservation.

Efforts focusing on the status and conservation requirements of individual species, and by association on the habitats in which they live, are very important and should be strongly encouraged. However, effective conservation in many parts of the world, especially in economically disadvantaged countries, also requires a broader approach, one that looks beyond often highly visible and emblematic taxa and focuses on sizeable areas that encompass a diversity of ecosystems.

In Madagascar, known for its exceptionally rich and highly endemic biota (Langrand \& Wilmé, 1997; Schatz, 2000) and for the threatened status of most of its remaining primary habitats (Du Puy \& Moat, 1996; Lowry et al., 1997), international scientists and their Malagasy collaborators began in the mid-1980s to call attention to the plight of several lemur species that have very narrow distributions and/or that were considered to be highly threatened. This led to the establishment of new parks and reserves, most of which were delimited to protect these lemurs, along with the thousands of additional species that co-occur with them (but see Kremen et al., 1999). The new protected areas were funded through integrated conservation and development projects (ICDPs), reflecting the recognition among many biologists, conservationists and development specialists that the long-term protection of forests in Madagascar could only be achieved by linking efforts to some form of local development. This was an attempt to provide economic alternatives to the unsustainable traditional land use practices that are largely responsible for the rapid degradation and destruction of Malagasy forests (see Adams \& Hulme, 2001, and the accompanying responses, for a commentary on community-based conservation).

The jury is still out on whether complex and expensive ICDPs can assure conservation beyond the initial period of donor support, but the prospects are not particularly encouraging. This is not to say that establishing new protected areas, and maintaining those that already exist, are a waste of time and money, clearly they are not. At the very least, officially recognized parks and reserves reduce human pressures and buy badly needed time to look for longer-term solutions; at best they may actually achieve effective conservation. But it is abundantly clear that Madagascar will not be able to assure adequate protection of all its existing network of parks and reserves, so hard choices will inevitably have to be made. It is equally evident that the current protected areas only encompass a portion of Madagascar's biodiversity, with many important areas and countless species receiving no protection whatsoever (Schatz et al., 2000).

In the past the process of setting priorities for locating new protected areas and for identifying existing ones that require special attention has largely been driven, at least in Madagascar, either by the presence of one or a few charismatic species (such as lemurs) or by the personal convictions of someone who felt passionately that 'their' area simply must be protected. Although this worked well in the late 1980s and early 1990s when funding was abundant, as donor support shrinks and habitat destruction continues unchecked, we must become smarter and more objective in setting priorities and allocating limited resources, especially if our overall goal is to conserve as much biodiversity as possible. What is now required is a comprehensive evaluation, using a broad range of plant and animal groups, to identify areas with particularly high concentrations of 
local endemics, threatened species and/or other taxa of high conservation importance (e.g. representatives of endemic higher taxa such as genera or families). By using existing data, and compiling additional information when necessary, the distributions of hundreds of taxa can be analysed simultaneously using various reserve selection algorithms, gap analysis and other techniques (Pendergast et al., 1999), providing a more logical and defensible basis for setting priorities. Such an approach would, for example, draw attention to the importance of several formations in Madagascar that contain many highly threatened plant species but which are poorly represented or completely absent from the network of protected areas (Ganzhorn et al., this issue).

This is where taxonomists can make a unique contribution to conservation. We are the stewards of vast amounts of data on species and their distributions, based for most groups on verified natural history collections in museums and herbaria, and for others such as mammals and birds on reliable sightings, that are ripe for analyses using geographical information system technologies and related methods. By carefully selecting representative portions of the flora and fauna whose taxonomy is well established and for which adequate collections or observations are available, we can provide recommendations based on a wealth of information that has till date remained largely untapped. In the process, not only can areas of exceptional overall conservation importance be identified using a variety of criteria, but we can also add significantly to our knowledge of threatened species in the process (e.g. Schatz et al., 2000). Although such an approach may not be suitable to all parts of the world, it will be applicable in many places where sound conservation decision making is most urgently needed, and without which large portions of the biodiversity will be lost within the next decade. By providing the data essential for implementing a more objective means of setting priorities, taxonomists can contribute a critical element that will strengthen support for conservation action. There is much to be gained by attracting more taxonomists to the global conservation effort.

Porter P. Lowry II, Head

Africa and Madagascar Department

Missouri Botanical Garden, USA

clo Laboratoire de Phanérogamie

Muséum National d'Histoire Naturelle

16 rue Buffon, 75005 Paris, France

e-mail: lowry@mobot.org

\section{References}

Adams, W.M. \& Hulme, D. (2001) If community conservation is the answer in Africa, what is the question? Oryx, 35, 193-200.

Du Puy, D.J. \& Moat, J. (1996) A refined classification of the primary vegetation of Madagascar based on the underlying geology: using GIS to map its distribution and to assess its conservation status. In Biogeography of Madagascar (ed. W.R. Lourenço), pp. 205-218. ORSTOM, Paris.

Kremen, C., Razafimahatratra, V., Guillery, R.P., Rakotomalala, J., Weiss, A. \& Ratsisompatrarivo, J.-S. (1999) Designing the Masoala National Park in Madagascar based on biological and socioeconomic data. Conservation Biology, 13, 1055-1068.

Langrand, O. \& Wilmé, L. (1997) Effects of forest fragmentation on extinction patterns of the endemic avifauna on the central high plateau of Madagascar. In Natural Change and Human Impact in Madagascar (eds S.M. Goodman and B.D. Patterson), pp. 280-305. Smithsonian Institution Press, Washington.

Lowry, P.P. II, Schatz, G.E. \& Phillipson, P.B. (1997) The classification of natural and anthropogenic vegetation in Madagascar. In Natural Change and Human Impact in Madagascar (eds S.M. Goodman and B.D. Patterson), pp. 93-123. Smithsonian Institution Press, Washington.

Pendergast, J.R., Quinn, R.M. \& Lawton, J.H. (1999) The gaps between theory and practice in selecting nature reserves. Conservation Biology, 13, 484-492.

Schatz, G.E. (2000) Endemism in the Malagasy tree flora. In Diversity and Endemism in Madagascar (eds W.R. Lourenço and S.M. Goodman), pp. 1-9. Mémoires de la Societé Biogéographie, Paris.

Schatz, G.E., Birkinshaw, C., Lowry, P.P. II, Randriantafika, F. \& Ratovoson, F. (2000) The endemic plant families of Madagascar project: integrating taxonomy and conservation. In Diversity and Endemism in Madagascar (eds W.R. Lourenço and S.M. Goodman), pp. 11-24. Mémoires de la Societé Biogéographie, Paris.

\section{Note from the Editor}

This is the last issue of Oryx to be published by Blackwell Science Ltd, and I wish to take this opportunity to thank Marion Laws, Sue Hewitt and all of the other members of the Blackwell team, both present and past, who have worked hard to ensure that the journal is a success.
For those readers wishing to contribute items to the Briefly, Letters, Conservation News, Grants and Opportunities, Meetings or Publications sections, please note that the deadlines for the January, April, July and October issues in 2002 will be 10 October 2001, 1 January, 2 April and 12 July 2002, respectively. From January 2002 onwards these dates will appear in the Instructions for Contributors. 